\title{
THE MEANING MAKING MODEL OF EATING DISORDERS (MESTA): A PRELIMINARY ANALYSIS OF THE MODEL
}

\author{
José H. Marco 1,5 , Montse Cañabate 2,3, Sandra Pérez², Verónica \\ Guillén ${ }^{1,5}$, Cristina Botella $a^{4,5}$ and Rosa Baños ${ }^{1,5}$ \\ ${ }^{1}$ University of Valencia; ${ }^{2}$ Catholic University of Valencia; ${ }^{3}$ Cardenal Herrera \\ CEU University; ${ }^{4}$ Jaume I University; ${ }^{5}$ Ciber Fisiopatología Obesidad y \\ Nutrición (CBO6/03) Institute of Health Carlos III, Madrid (Spain)
}

\begin{abstract}
Studies of people with eating disorders (ED) have indicated that meaning in life is negatively associated with psychopathology, suicide risk, and emotional instability in people with ED. The aim of this study was to analyze the mediating role of meaning in life and its dimensions in the relationship between body dissatisfaction and the symptoms of ED, and to provide evidence that supports the meaning making model of eating disorders (MESTA, in Spanish). 292 Participants diagnosed with ED completed the Purpose in Life Test (PIL), the Eating Attitudes Test (EAT), and the Multidimensional Body-Self Relations Questionnaire (MBSRQ-AS). Multiple mediation analyses were performed. Meaning in life was a mediator between body dissatisfaction and ED psychopathology. The dimension of Satisfaction and meaning in life had a greater mediating role. Meaning in life could be an important variable in the maintenance of ED. The MESTA could be a useful model for understanding the psychopathology of ED.

KEY WORDS: meaning in life, body dissatisfaction, diet, anorexia nervosa, bulimia nervosa.

\section{Resumen}

Según estudios previos el sentido en la vida está asociado negativamente con la psicopatología, el riesgo de suicido y la inestabilidad emocional en personas con trastornos alimentarios (TA). El objetivo de este estudio fue analizar el papel mediador del sentido de la vida y sus dimensiones en la relación entre la insatisfacción corporal y la sintomatología del TA y aportar pruebas que apoyen un modelo de elaboración del sentido de los trastornos alimentarios (MESTA). 292 personas diagnosticadas con TA (93,5\% mujeres) contestaron el "Test de propósito en la vida" (PIL), el "Test de actitudes hacia la comida" (EAT) y el "Cuestionario multidimensional de relaciones entre el cuerpo y el yo" (MBSRQAS). Se realizaron análisis de mediación múltiple. El sentido en la vida medió la asociación entre la insatisfacción corporal y la psicopatología del TA. La dimensión de Satisfacción y sentido tuvo un papel mediador mayor. El sentido en la vida
\end{abstract}

Correspondence: José H. Marco, Faculty of Psychology, University of Valencia, Av. Blasco Ibañez, 21, 46010 Valencia (Spain). E-mail: jose.h.marco@uv.es 
podría ser una variable importante en el mantenimiento de los TA. EI MESTA puede ser un modelo útil para la comprensión de la psicopatología de los TA.

PALABRAS CLAVE: sentido en la vida, insatisfacción corporal, dieta, anorexia nerviosa, bulimia nerviosa.

\section{Introduction}

Eating disorders (ED) are serious mental disorders associated with significant morbidity and mortality, as well as high public health costs (Arcelus, Mitchell, Wales, \& Nielsen, 2011). With a prevalence of between 11 and 15\% in women (Allen, Byrne, Oddy, \& Crosby, 2013), these disorders are associated with significant feelings of anguish, deteriorated social functioning, and a high risk of depression, substance abuse, anxiety, and suicide (Crow et al., 2009). Although we have evidence-based treatments for EDs, mainly Cognitive Behavioral Therapy (CBT) (Fairburn, 2008; Fairburn et al., 2009; National Institute for Clinical Excellence, 2017), review studies estimate that dropout rates can range between $20 \%$ and $40 \%$, with high relapse rates (Bulik, Berkman, Brownley, Sedway, \& Lohr, 2007; Hay, 2013; Smink, Hoeken, \& Hoek, 2013), and longitudinal studies have found that $20 \%$ of patients remain chronically ill (Steinhausen, 2002). One of the main difficulties in the treatment of ED is rejection and resistance to change. This resistance occurs because the patient may not recognize the ED as a problem, making collaboration in treatment difficult (Macdonald, Hibbs, Corfield, \& Treasure, 2012). Thus, treatments could benefit from including new intervention components designed to increase motivation and adherence.

There is a broad consensus that body image is a central variable in the etiology of ED (Stice, 2016; Forrest, Jones, Ortiz, \& Smith, 2018). Cash (2011) suggested that the body image is made up of two dimensions: evaluation and involvement. Evaluation refers to each person's satisfaction or dissatisfaction with his/her body, and beliefs and judgments about it. Involvement refers to the importance the body has in the person's self-concept, cognitively, behaviorally, and emotionally. Regarding the evaluation of appearance, negative feelings about the body and body dissatisfaction have been identified as primary risk factors for the development of ED (for example, Gordon et al., 2020; Stice, Marti, \& Durant, 2011; Striegel-Moore \& Bulik, 2007). However, Stice, South, and Shaw (2012) indicated that few studies have analyzed the mediating factors between negative body image and ED psychopathology, and they suggest that there is a need for studies that also explore how risk factors interact with each other. In this regard, some studies in the non-clinical population have found that perfectionism, selfesteem, and sociocultural pressure moderate the association between body dissatisfaction and the ED psychopathology (Brechan \& Kvalem, 2015; Rosewall, Gleaves, \& Latner, 2020). In addition, the relationship between body dissatisfaction and ED psychopathology has been found to be mediated by depression, negative affect, and self-esteem (Cruz -Sáez, Pascual, Wlodarczyk, \& Echeburúa, 2018; Perpiñá \& Borra, 2010). However, all the studies mentioned above have been 
carried out in non-clinical populations. Thus, as Stice et al. (2012) indicated, it is necessary to analyze the variables that might mediate the relationship between body dissatisfaction and the ED psychopathology in studies with a clinical population. In this regard, several studies have shown that meaning in life could be an important variable in people with ED (for example, Marco, Cañabate, Pérez, \& Llorca, 2017).

The study of meaning in life as a protective variable against psychopathology was originally proposed by Viktor Frankl (1959). Although there are different definitions of the construct (Martela \& Steger, 2016; Wong, 1998), most of them share the idea that people with a high level of meaning in life feel that their life is organized towards an important vital purpose or goals within a coherent and organized whole. Their contribution to this whole is considered their sole and inescapable responsibility, leading them to feel that life is worth living despite their circumstances. In contrast, people with low meaning in life perceive their life as fragmented and incoherent, with no vital goals. Nothing seems valuable in their future, and they perceive that their life, and what they do in it, is unimportant.

Numerous studies carried out with patients without a diagnosis of ED have shown that the presence of meaning in life is associated with better psychological adjustment and greater well-being (Glaw, Kable, Hazelton, \& Inder, 2017), whereas low meaning in life is associated with a higher risk of suicide (e.g., Costanza, Prelati, \& Pompili, 2019), more depressive symptoms (Volkert, Schultz, Brütt, \& Andreas, 2014), more psychopathology (Schulenberg, Strack, \& Buchanan, 2011), and greater emotional instability (Lorca, Pérez, Giner, \& Marco, 2019; Marco, García-Alandete, Pérez, \& Botella, 2014). Furthermore, meaning in life has also been found to be a positively associated with age (Steger, Oishi, \& Kashdan, 2009).

However, to date, studies on the possible mediating role of meaning in life in the psychopathology of patients with ED are scarce. The cross-sectional study by Marco et al. (2017) revealed that patients with ED had lower levels of purpose and meaning in life than the general population. Furthermore, meaning in life was also found to be negatively related to concern about being overweight and negative attitudes towards food. Furthermore, the results of that study indicated that meaning in life was negatively associated with emotional instability and suicidal ideation. Subsequently, Marco, Cañabate, Llorca, and Pérez (2020) conducted a longitudinal study and found that meaning in life was a buffer in the relationship between dysfunctional attitudes and behaviors towards food, hopelessness, and suicidal ideation. Regarding the relationship between meaning in life and body satisfaction, studies carried out with patients diagnosed with ED found that meaning in life was highly and positively related to body satisfaction (Marco et al., 2017). Thus, all these studies suggest that meaning in life could be a mediating factor in the course of the ED psychopathology.

Marco et al. (2020) proposed the meaning making model of eating disorders (MESTA in Spanish) as a theoretical framework to integrate the results found so far and suggest future research hypotheses. The MESTA is based on the meaning- 
making model, which has been used fundamentally in the field of post-traumatic stress disorder and grief (e.g., Gillies \& Neymeyer, 2006; Park, 2010).

The meaning-making model (Park, 2010) differentiates between global meaning, situational meaning, meaning making processes, and meanings made. The global meaning would consist of the feeling that life is coherent and understandable and has a purpose and actions directed toward vital tasks that are of great importance to us. The situational meaning refers to the immediate meaning or interpretation we create in each new situation that is potentially distressing or stressful. To the extent that the situational meaning is incongruous with the global meaning, the subject will experience more or less suffering. The suffering caused by this discrepancy will set meaning making processes in motion. These processes consist of a set of cognitive, behavioral, and emotional processes through which people try to reduce the discrepancy between the situational meaning and the global meaning. In this way, a new meaning of the world, of themselves, and of their lives would be created, and, consequently, people may experience a reduction or increase in meaning in life. This process, when it unfolds properly, allows people to adjust better to stressors and increase their meaning in life and identity. However, if it does not take place properly, it can lead to increased anxiety, depression, and suffering.

According to the MESTA (Marco et al., 2020), the components of global meaning in people with ED would be: (a) basic assumptions about the world and personal beliefs: "thin people are beautiful"; "I am not worth anything"; "I need to have a good appearance to be accepted by others"; (b) objectives, ideals, and goals towards which they are directed: "to become Ana or Mia"; "to achieve a weight of $50 \mathrm{~kg}$ "; "to be the best", "to be perfect"; "to control my body"; and (c) feelings that my life is important and that it has inherent value, that is, a life worth living: "outside the AN my life has no value"; and "AN is the most important thing in my life". Thus, in people with ED, their global meaning would be: "Within the AN, my life is coherent because I control my body, I am losing weight, and I have my identity. This is the most important goal for me " (you can see the MESTA in the Appendix).

The MESTA suggests that when people with high vulnerability to ED (e.g., women with extreme perfectionism, emotional instability, low self-esteem, need for self-control, and body dissatisfaction) face a distressing event (e.g., "a significant increase in weight"), a situational meaning would be created (e.g., "People will reject me with this body"). If the situational meaning of the event violates or contradicts their global meaning (for example, "I am perfect"; " My goal is to lose weight"), the person will experience distress and other negative emotions and begin to develop cognitive and behavioral strategies to reduce these discrepancies through meaning making processes. One of these strategies could be the appearance of intrusive thinking or rumination focused on the emotions and thoughts that distress the patient (Scott \& Snyder, 2005) (e.g., "Because I am not the thinnest of my friends, everyone will reject me, and so I need to control my weight and my food"; "If I cannot control my binging, I will not be able to control 
anything in my life"; and "I need more control over my body and my food to achieve success in my life"). Thus, one of the functions of the cognitive and behavioral symptoms of ED would be to try to reduce the discrepancy between the global meaning and the situational meaning (Marco et al., 2020). In the initial stages of the ED, the situational meaning would be integrated into the previously constructed global meaning (assimilation process) (e.g., when experiencing negative emotions due to weight gain, the patient decides to eat a restrictive diet and feels thinner and, therefore, interprets: "By dieting, I will lose weight. I will not lose control of my body, and so I will continue to be Ana"; "My life has meaning because of the anorexia nervosa".

The MESTA suggests that, in people with ED, behaviors and attitudes towards food are coherent and congruent with the goals or values that guide their lives ("I have to control my body"; "I need to look good"; " I'm perfect "; "to be Ana or Mia"). These behaviors can provide a sense of control in the short term because they allow them to control their bodies and lose weight. These short-term results lead to increased self-esteem and a sense of control over their bodies and lives (Brockmeyer et al., 2013; Fairburn, 2008). Therefore, in the short term, people with ED have dysfunctional strategies that give them a sense of coherence, purpose, importance, and an identity (Fox \& Leung, 2008; Serpell, Treasure, Teasdale, \& Sullivan, 1999), thus creating a new situational meaning consistent with their global meaning ("After losing weight I am attractive, I control my body, and I am perfect"). Some authors have suggested that internal reinforcement through the feeling of achievement and mastery can be quite important in maintaining ED, even more so than social reinforcement (Garner \& Bemis, 1982; Vitousek \& Ewald, 1993). Consequently, the MESTA suggests, as other authors have previously stated (Gulliksen, Nordbø, Espeset, Skårderud, \& Holte, 2016), that the characteristic symptoms of ED are dysfunctional ways of controlling the body with which they are dissatisfied, negative emotions, and emotional challenges they have experienced at any given time in their lives (Martín, Cangas, Pozo, Martínez, \& López, 2008).

According to the MESTA, people with ED are oriented towards dysfunctional goals and vital values, such as controlling their body, weight, and food and avoiding negative emotions, which, in the long term, keeps them from developing an authentic feeling of meaning in life. In addition, ED would keep them from achieving vital goals and objectives related to the main sources of meaning in life. Several studies have analyzed the sources of meaning in the general population: a) having good family relationships (Lambert et al., 2010); b) having good interpersonal relationships, health, personal growth (Grounden \& Jose, 2014); c) loving someone or something; and (d) having a creative activity that allows them to build something unique and creative and turn a source of suffering into a personal triumph (Frankl, 2006). Longitudinal studies have found that people with resistant ED have problems with family relationships, a lack of adequate interpersonal relationships, chronic illnesses, or very poor health as a consequence of ED. They may even have a disability and be unemployed (Touyz \& Hay, 2015) or 
experience feelings of hopelessness (Robinson, Kukucska, Guidetti, \& Leavey, 2015), problems with their identity (Stein \& Corte, 2007), and poor quality of life (Tomba, Tecuta, Schumann, \& Ballardini, 2017). This would explain why people with ED have low meaning in life (Marco et al., 2017).

According to the MESTA, by reducing the discrepancy between the situational meaning and an adaptive global meaning composed of adaptive goals and values, the person's sense of coherence, purpose, and importance in life will increase, thus enhancing their meaning in life and identity. This would be done by modifying the global meaning by constructing a new situational meaning (accommodation process) (for example, after gaining weight, and with the help of his/her therapist, the patient is able to think that "being perfect and weighing less than 50 kgs is not an adequate vital goal"). This process will lead to a reduction in negative emotions, intrusive thoughts, and the psychopathology of ED. Therefore, meaning in life would be a moderating factor (Marco et al., 2020) or a mediator of the ED psychopathology.

Although, as mentioned above, some studies have indicated that meaning in life is a variable associated with the psychopathology of ED, to date no study has analyzed whether meaning in life is a mediator between an important risk factor, such as body dissatisfaction, and the ED psychopathology, as suggested by the MESTA.

Thus, we can hypothesize that meaning in life will be a mediator in the association between negative body image and ED psychopathology. And more specifically, regarding the dimensions of meaning in life, we can hypothesize that the dimension of importance (Satisfaction and meaning in life) will have a greater mediating role than the dimension of purpose (Vital Goals).

The objectives of this study are: a) to analyze the mediating role of meaning in life in the relationship between body dissatisfaction and the symptoms of ED; b) analyze the mediating role of the dimension of satisfaction and meaning in life in the relationship between body dissatisfaction and the symptoms of ED; c) analyze the mediating role of the dimension of goals and vital values in the relationship between body dissatisfaction and the symptoms of ED; and d) analyze which dimension has a higher percentage of explained variance in the mediation.

\section{Methods}

\section{Participants}

The sample was composed of 292 participants diagnosed with ED from two mental health units specialized in ED in different cities in Spain. Inclusion criteria were: patients who fulfilled the DSM-5 criteria for ED (APA, 2013) and were undergoing psychological treatment. Exclusion criteria were having a diagnosis of moderate or severe intellectual disability. Participants were European Whites. Participation was voluntary, and they gave their informed consent and did not 
receive any compensation. Ethical approval for this study was granted by the ethics committee. Participants were recruited consecutively.

Of the 292 participants, $93.5 \%$ were women, $n=273$, and $6.5 \%$ were men, $n=19$. The ages of the participants ranged from 12 to 60 years, with a mean age of $24.21(S D=11.01)$ years. 77 , had primary education, 148 , had secondary education, and 67, had higher education. Regarding marital status, 162, were single, 121, were married or living with a partner, and 9, were separated. Regarding the diagnoses, 84 met the diagnostic criteria for Restrictive Anorexia Nervosa (RAN), 67 for Bulimia Nervosa (BN), 32 for AN Purgative (ANP), 38 for APD, and 71 for Other Specified Feeding and Eating Disorder (OSFED). In addition, 68 , had a comorbid diagnosis of personality disorder.

\section{Instruments}

a) Structured Clinical Interview for DSM-5 Disorders - Clinician Version (SCID-5CV; First, Williams, Karg, \& Spitzer, 2015). The SCID-5-CV was translated ad hoc for this research. This is an interview used to diagnose the main DSM-5 disorders (APA, 2013). Although it is not validated in the Spanish population, it has shown adequate psychometric properties in the Brazilian population (sensitivity> 0.70; Specificity> 0.80; $\kappa>0.75$ ) (Osorio et al., 2019).

b) Structured Clinical Interview for Personality Disorders DSM-5 (SCID-5PD; First, Williams, Benjamin, \& Spitzer, 2015). The SCID-5PD was translated ad hoc for this research. The SCID-5PD is a semi-structured interview used to make the diagnosis of personality disorder based on the DSM-5 (APA, 2013). Although we do not have psychometric properties of this version, the previous version, the SCID-II (First, Gibbon, Spitzer, Williams, \& Benjamin, 1999) has shown adequate psychometric properties ( $\kappa=0.48-0.98)$ (Maffei et al., 1997).

c) Purpose in Life Test (PIL; Crumbaugh \& Maholick, 1969). For this research we utilized the Spanish version of 10 items (Garcia-Alandete, Rosa, \& Sellés, 2013). This questionnaire aims to measure meaning and purpose in life. It is a scale made up of 10 items rated on a Likert-type scale with seven response options related to different aspects of meaning in life, ranging from enthusiasm to boredom and presence or absence of goals and purposes in life. Total scores range from 10 to 70 , with higher scores indicating greater meaning / purpose in life. The PIL-10 is made up of two subscales: a) Satisfaction and meaning in life, which evaluates the perception and general assessment of meaning in life and satisfaction with life and the importance of one's life, through items such as "Life seems to me: Completely routine/Always exciting "; "If I could choose: I would never have been born/I would have nine other lives just like this one"; or "When I think about my own life: I wonder why I exist / I always find reasons to live; b) Vital goals and purpose assesses a motivational factor related to the establishment of specific vital goals and purposes, through items such as "In life I have: No goal or desire/Many defined goals and desires"; or "I consider that my ability to 
finding a meaning, a purpose, or a mission in life is: Virtually none/Very great". In our sample, this instrument showed adequate psychometric properties, with a Cronbach's $\alpha$ of .92 for the Satisfaction and meaning in life subscale, and a Cronbach's $\alpha$ of.89 for the Vital goals subscale.

d) Eating Attitudes Test (EAT-40; Garner \& Garfinkel, 1979). The EAT-40 assesses attitudes and behaviors associated with food. The Spanish version has 40 items organized into three subscales and responded to on a 6-point Likert scale: (a) Diet and concern about food, which assesses thoughts, beliefs and behaviors characteristic of people with ED ("I feel that food controls my life "; " I feel terrified of becoming overweight"; " I cut my food into small pieces ";

" I go on a diet "; (b) Perceived social pressure and discomfort with food, which evaluates emotions and thoughts about food and the perceived pressure that others force one to eat ("I avoid eating when I'm hungry"; "I feel that others would like me to eat more"; and (c) Psychobiological disorders, which assesses maladaptive behaviors in EDs ("I take laxatives"; "I vomit after eating"). The instrument offers good psychometric properties and high reliability in patients with $\mathrm{AN}(\alpha=.93)$ and $\mathrm{BN}(\alpha=.92)$ in the Spanish version (Castro, Toro, Salamero, \& Guimera, 1991). In our sample, it showed excellent reliability $(\alpha=.90)$.

e) Multidimensional Body-Self Relations Questionnaire - Appearance Scales (MBSRQ-AS; Cash, 2000), Spanish version by Roncero, Perpiñá, Marco y Sanchez-Reales (2015). The MBSRQ This is a self-administered questionnaire composed of 34 items grouped into 5 subscales (Appearance evaluation, Appearance orientation, Satisfaction with body areas, Concern about being overweight, and Self-classified weight). It consists of Likert-type items with response categories ranging from $1=$ strongly disagree to $5=$ strongly agree. For this study, we used the Appearance Evaluation scale. This scale is made up of seven items that assess beliefs and feelings of satisfaction or dissatisfaction with one's physical attractiveness and appearance. High scores on this scale reflect positive feelings and high satisfaction with one's appearance. In our sample, the Cronbach $\alpha$ index for men and women is $\alpha=.88$. We use the Spanish version (Roncero, Perpiñá, Marco, \& Sanchez-Reales, 2015).

\section{Procedure}

To carry out the initial evaluation, the participants were contacted, and an individual evaluation session was carried out to establish the diagnosis of ED and personality disorders using the SCID-5 (First et al., 2015). Given that this interview was not available in Spanish at the time of the research, the questions were translated and back-translated by two bilingual experts (English-Spanish) to evaluate the ED and personality disorders. The evaluation interview and the diagnosis were conducted by a clinical psychologist with a doctorate in psychology and more than 10 years of experience in the evaluation of ED and personality 
disorders. Subsequently, the participants completed the MBSRQ, PIL, and EAT questionnaires.

Data analysis

All the variables met the statistical assumptions (normal distribution of the data, linear relationship between the independent variable and each of the dependent variables, homoscedasticity of the residuals, etc.). First, descriptive statistics were calculated for all the variables. Subsequently, zero-order correlations (Pearson's coefficient) were carried out. Finally, three multiple mediation analyses were performed. In the first analysis, we took the Appearance evaluation (MBSRQ) as the predictor variable, Meaning in life (PIL) as the mediating variable, and ED attitudes and behavior (EAT) as predicted variables. In the second analysis, the mediating variable was the Satisfaction and meaning in life subscale. In the third, the mediating variable was the Vital goals and purposes subscale. All the analyses were performed with the age variable controlled. We used the bootstrap method (1000 replications) and calculated the total, direct, and indirect effects, obtaining the variance explained (adjusted R2) by the mediation. The calculations and the mediation model were performed with the JASP (JASP Team, 2019) statistical program following the Baron and Kenny (1986) procedure.

\section{Results}

Table 1 shows the means and correlations between the variables studied. Meaning in life (PIL) had a high and positive correlation with Appearance evaluation (MBSRQ) and a moderate and negative correlation with Diet, Perceived social pressure and discomfort with food, and Psychobiological attitude disorders (EAT). The Satisfaction and meaning in life (PIL) subscale had a moderate and positive correlation with Appearance evaluation and a moderate and negative correlation with Diet, Perceived social pressure and discomfort with food, and Psychobiological attitude disorders (EAT). Vital goals and purpose (PIL) had a moderate and positive correlation with Appearance evaluation and a low and negative correlation with Diet, Perceived social pressure and discomfort with food, and the Psychobiological attitude disorders (EAT). On the other hand, Appearance evaluation had a strong and negative correlation with Diet, a moderate correlation with Psychobiological disorders, and a low correlation with Perceived social pressure and discomfort with food (EAT). The other correlations can be seen in Table 1. 
Table 1

Correlations between variables

\begin{tabular}{|ll|c|c|c|c|c|c|c|}
\hline & Variable (instrument) & $M(S D)$ & 2 & 3 & 4 & 5 & 6 & 7 \\
\hline 1. & Meaning in life (PIL) & $43.98(12.51)$ & $.95^{*}$ & $.89^{*}$ & $.50^{*}$ & $-.35^{*}$ & $-.30^{*}$ & $-.34^{*}$ \\
\hline 2. & Satisfaction and meaning (PIL) & $23.61(8.08)$ & & $.71^{*}$ & $.48^{*}$ & $-.36^{*}$ & $-.30^{*}$ & $-.35^{*}$ \\
\hline 3. & Vital goals and purpose (PIL) & $20.25(5.39)$ & & & $.42^{*}$ & $-.27^{*}$ & $-.24^{*}$ & $-.25^{*}$ \\
\hline 4. & Appearance evaluation (MBSRQ) & $2.50(0.95)$ & & & & $-.50^{*}$ & $-.27^{*}$ &,$- 38^{*}$ \\
\hline 5. & Diet and preoccupation (EAT) & $26.82(18.56)$ & & & & & $.72^{*}$ & $.74^{*}$ \\
\hline 6. & Social pressure (EAT) & $7.32(6.19)$ & & & & & & $.49^{\star}$ \\
\hline 7. & Psychobiological disorders (EAT) & $3.71(3.10)$ & & & & & & \\
\hline
\end{tabular}

Notes: PIL= Purpose in Life Test; MBSRQ $=$ Multidimensional Body Self Relations Questionnaire; EAT $=$ Eating Attitudes Test; Diet and preoccupation $=$ Diet and preoccupation for food; Social pressure $=$ Perceived social pressure and discomfort with food. ${ }^{\star} p<.01$.

As Table 2 reveals, Meaning in life (PIL) showed a partial multiple mediation effect in the association between Appearance evaluation and the Diet subscale (direct effect $\beta=-8.60, p<.001$ ) (indirect effect $\beta=-1.14, p<.05$ ), the Perceived social pressure and discomfort with food subscale (direct effect $\beta=-1.19, p<.01$ ) (indirect effect $\beta=-0.66, p<.001$ ), and the Psychobiological disorders subscale (direct effect $\beta=-0.83, p<.001$ ) (indirect effect $\beta=-0.30, p<.01$ ) in people with ED (see Figure 1).

\section{Figure 1}

Meaning in life mediates the relationship between body satisfaction and psychopathology of eating disorders

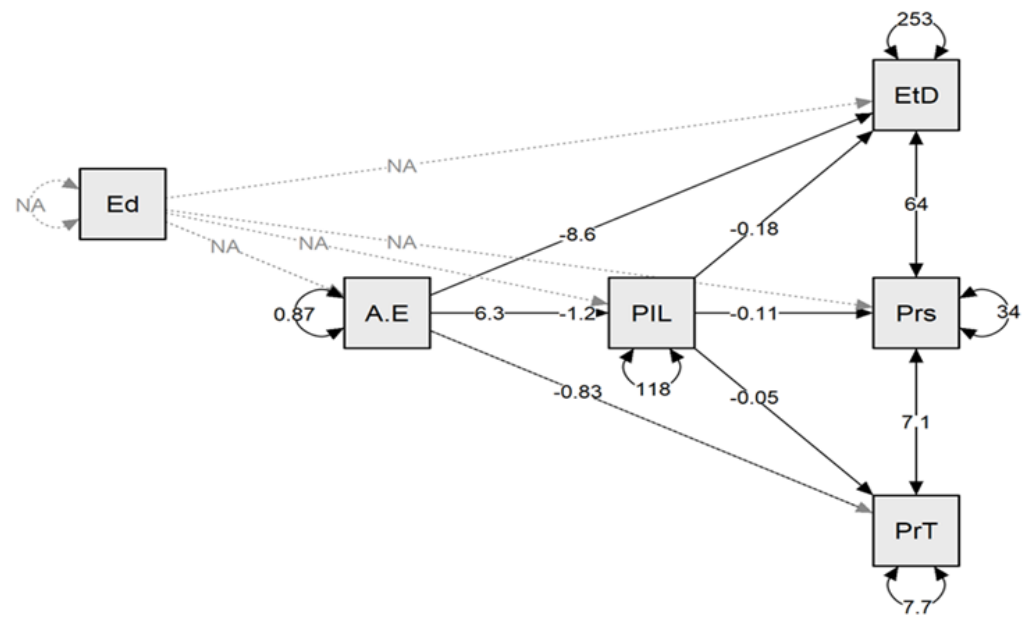

Note: $\mathrm{Ed}=$ Age; $\mathrm{AE}=$ Appearance evaluation; $\mathrm{PIL}=$ Purpose in life; $\mathrm{EtD}=$ Subscale of Diet and preoccupation with food of the Eating Attitudes Test (EAT); Prs= Subscale of Perceived social pressure and discomfort with food of the EAT; PrT= Subscale of Psychobiological Disorders of the EAT. 





Furthermore, as Table 3 shows, the Satisfaction and meaning in life (PIL) subscale showed a partial multiple mediation effect in the association between Appearance Evaluation and the Diet subscale (direct effect $\beta=-8.40, p<.001$ ) (indirect effect $\beta=-1.35, p<.01$ ), the Perceived social pressure subscale and Discomfort with Food (direct effect $\beta=-1.17, p<.01$ ) (indirect effect $\beta=-0.67, p<$ .01 ), and the Psychobiological disorders subscale (direct effect $\beta=-0.77, p<.001$ ) (indirect effect $\beta=-0.36, p<.001$ ) in people with ED (Figure 2).

\section{Figure 2}

Satisfaction and meaning in life mediates the relationship between body satisfaction and psychopathology of eating disorders

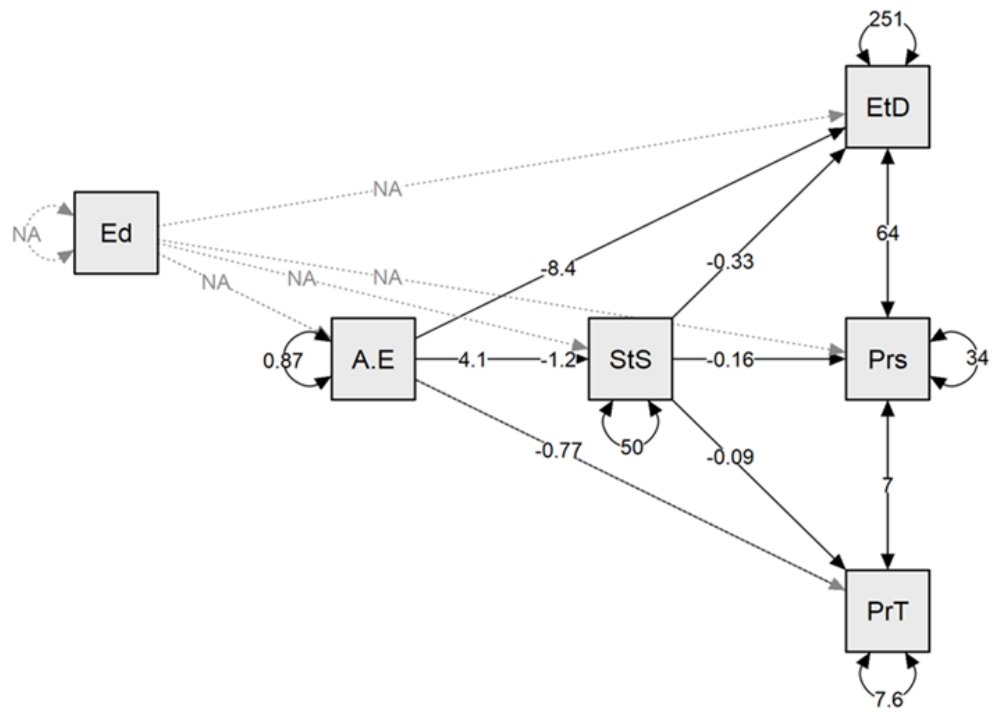

Note: $\mathrm{Ed}=\mathrm{Age} ; \mathrm{AE}=$ Appearance evaluation; $\mathrm{Sts}=$ Satisfaction and meaning subscale; $\mathrm{EtD}=$ Diet and preoccupation for food of the Eating Attitudes Test (EAT); Prs= Perceived social pressure subscale and discomfort with food of the EAT; PrT= Psychobiological disorders subscale from the EAT.

Finally, as Table 4 reveals, the Vital goals and purposes (PIL) subscale showed a complete mediating effect in the association between Appearance evaluation and the Diet subscale (direct effect $\beta=-9.31, p<.001$ ) (indirect effect $\beta=-0.44, p=$ 0.33 ) and Psychobiological disorders (direct effect $\beta=-1.02, p<.001$ ) (indirect effect $\beta=-0.11, p=.13$ ). Finally, the Vital goals and purposes (PIL) subscale showed a partial mediation effect between Appearance evaluation and the Perceived social pressure and discomfort with food subscale (direct effect $\beta=-1.48, p<.001$ ) (indirect effect $\beta=-0.38, p<.01$ ) (Figure 3). 


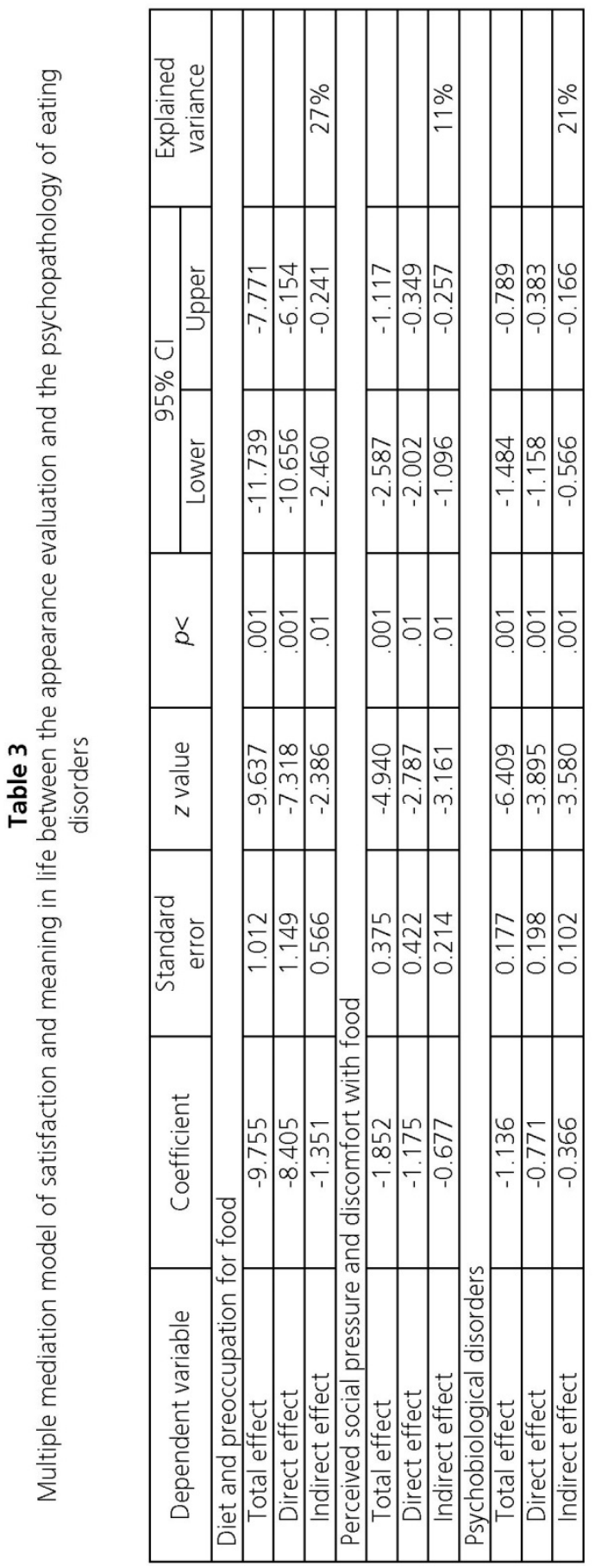




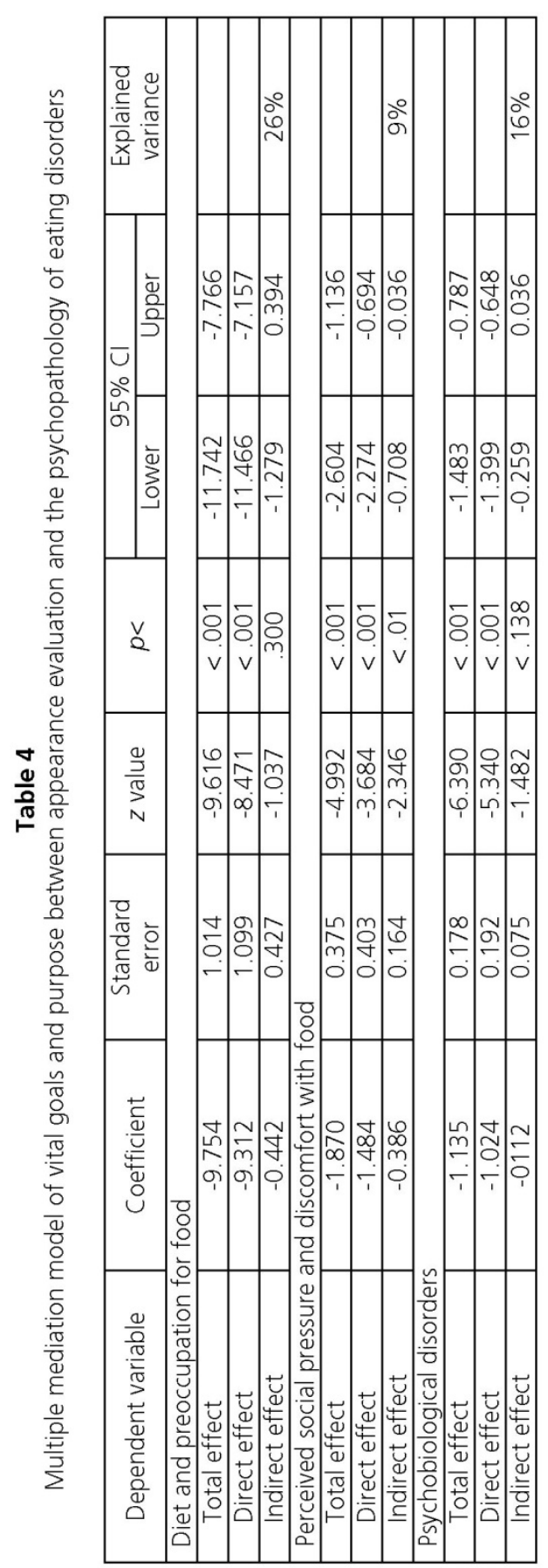




\section{Figure 3}

Life goals and purpose mediates the relationship between body satisfaction and the psychopathology of eating disorders

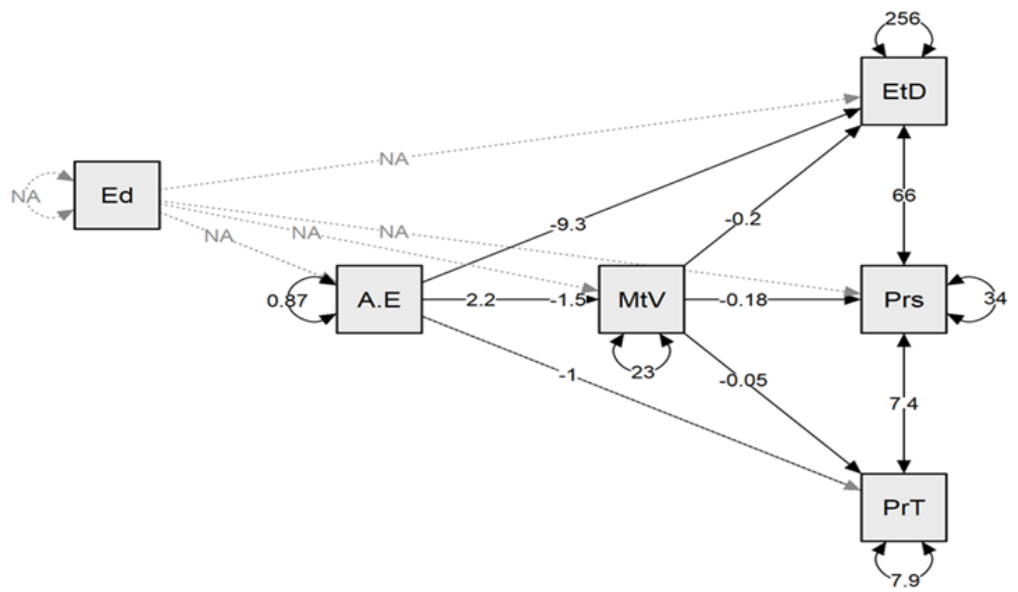

Note: $\mathrm{Ed}=$ Age; $\mathrm{AE}=$ Appearance evaluation; $\mathrm{MtV}=$ Vital goals and purpose subscale; EtD=Diet and preoccupation for food of the Eating Attitudes Test (EAT); Prs=Perceived social pressure subscale and discomfort with food of the EAT; PrT= Psychobiological disorders subscale of the EAT.

\section{Discussion}

The results of the present study reveal that meaning in life (total PIL) showed a multiple mediation effect in the association between appearance evaluation and attitudes, beliefs, and behaviors characteristic of people with ED (Diet subscale), eating discomfort (Perceived social pressure and eating discomfort subscale), and dysfunctional behaviors characteristic of people with ED (Psychobiological disorders subscale).

When analyzing the mediating role of each dimension of meaning in life, the results indicate that the Satisfaction and meaning in life dimension had the strongest mediating role between appearance evaluation and dysfunctional attitudes and behaviors towards food and the body (with the three subscales Diet, Perceived social pressure and discomfort with food, and Psychobiological disorders), taking into account that the percentage of variance explained was slightly higher in the Satisfaction and meaning subscale than in the Vital goals and purpose subscale.

Thus, these results suggest that, in people diagnosed with ED, the Importance dimension of meaning in life (assessed with the Satisfaction and meaning subscale), which is the affective dimension that refers to the feeling that one has found a unique, authentic, and genuine meaning in life, is satisfied with life, and feels important, is more important than the Purpose dimension (assessed by the Vital goals and purpose subscale), which refers to people's experience that their life is oriented and guided by life goals and aims. Thus, in people with ED, it is 
important to have a life goal that guides their life, but it is even more important for these goals to be significant, unique, and make them feel that life is worth living, thus allowing them to build meaning in life (Frankl, 2006).

Our results are consistent with the results of previous studies that found meaning in life to be moderately and negatively related to preoccupation with overweight and negative attitudes towards food (Marco et al., 2017; 2020). However, in the present study, we go a step further by analyzing its mediating role between two central variables in ED psychopathology, body image (Stice, 2016) and dysfunctional attitudes, beliefs, and behaviors towards food, weight, and the body (Forrest et al., 2018).

It should also be noted that our results indicate that meaning in life is positively associated with body image, i.e., greater meaning in life is linked to greater body satisfaction. In this research, we have used the body satisfaction component, but future research should test whether other components of body image are also related to meaning in life, such as appearance orientation (Cash, 2000) or emotional involvement with the body (Orbach \& Mikulincer, 1998).

Our results, from the perspective of the MESTA, have some clinical implications. On the one hand, this model suggests, as other authors have previously proposed (e.g., Fava, 2016; Pike \& Olmsted, 2016), that it is necessary to broaden the focus of treatment beyond behavioral symptoms (binge eating and vomiting), weight gain, and eating normalization. Thus, we would suggest adding or integrating an intervention component from the MESTA to evidence-based treatments such as CBT for ED (Fairburn, 2008) for people diagnosed with ED who have low meaning in life. In these cases, when the patient's medical condition allows it (with a normalized BMI and a moderate frequency of binge eating and vomiting), the treatment could be oriented towards increasing meaning in the person's life by improving each of the dimensions of meaning. The first objective would be to increase the feeling of coherence in patients' lives by making them aware of the change in their global meaning and situational meaning before and after the onset of the ED (keeping in mind that the ED behaviors and attitudes would be a form of maladaptive coping with the threatening event the patient has to face). A first step would be to make patients aware of the meaning making process that they have undergone to transform their global meaning into the identity of anorexia or bulimia. Increasing the sense of coherence in their life, through techniques such as "The Book of Life" (Niemeyer, 2000), could make them aware of the lack of coherence in their goals and values and help them to reorganize them into a coherent whole from which to create a life worth living. Second, psychotherapy should be oriented towards exploring and understanding the goals, values, and sources of meaning in their life before the onset of ED and during ED. The aim would be to make them see that, even now, they have the chance to freely build a life worth living, oriented towards adaptive and positive goals, values, and sources of meaning (e.g., positive interpersonal relationships, quality of life, realization of goals with an adaptive global meaning). Third, we would orient psychotherapy towards the dimension of Importance by making 
patients experience that they are back in control and have the responsibility of achieving goals within the overall goal of building a life worth living, in which they are the important piece, and that their life is important. The need for control is a central characteristic of people with ED (Fairburn, 2008). Thus, by offering people with ED the opportunity to choose, decide, and orient their life goals and the purpose in their lives towards sources of meaning compatible with a fulfilling life, we are supporting specific goals the patient wants, which would be an important motivational factor (Tomba et al., 2017).

On the other hand, the MESTA perspective may be interesting for treating severe and resistant patients, that is, patients whose life is totally oriented towards dysfunctional sources of meaning, such as ED, resulting in depression, hopelessness, and poor quality of life. In this group of patients, assessing the meaning in life and carrying out an intervention that guides them towards adaptive sources of meaning could be motivating. Considering the high dropout and relapse rates found in studies of treatment efficacy for ED (Hay, 2013; Smink et al., 2013; Steinhausen, 2002), it is essential to orient psychotherapy towards important and vital goals for people with ED, and this is perhaps the main contribution the MESTA would make to current models of ED.

Our work has some limitations. First, it has a cross-sectional design, which limits the causal inferences that can be drawn from this research, and longitudinal studies are needed to determine causality between the variables. Second, although our results suggest the mediating effect of meaning in life, it should be noted that the percentage of variance explained is low for the subscales of Perceived social pressure and discomfort with food and Psychobiological disorders. These results are in line with previous studies in non-clinical populations, where a low percentage of variance was found in the relationship between meaning in life and healthy eating (Brassai, Piko, \& Steger, 2015) and ED symptoms (Góngora, 2014). Thus, these results suggest that the predictive power of meaning in life in specific eating symptomatology (e.g., EAT) could be lower than in associated and nonspecific ED symptomatology, such as hopelessness, suicidal ideation, and emotional and behavioral instability, where it would have a greater predictive role, as found in previous studies (e.g., Marco et al., 2020). Third, the fact that the percentage of variance explained was low may be due to the presence of other variables that moderate this mediation but have not been taken into account in our study (e.g., emotional dysregulation). Thus, future studies should conduct a moderated mediation study to introduce these important variables in the ED psychopathology. Fourth, we used only self-report questionnaires to measure the variables studied. Although the instruments used have shown high reliability in our sample, these variables would have to be confirmed in interviews. In addition, this study did not use a random selection of patients. They were selected sequentially as they arrived at the mental health services, which reduces the generalizability of the results.

Another limitation of the study is that the sample presents considerable variability in the age of the participants. Given that meaning in life is a variable 
that is positively associated with age, the multiple mediation analysis was conducted with age controlled. In addition, we used the PIL, which is an instrument that has been shown to have adequate psychometric characteristics in Spanish adolescents (García-Alandete, Gallego Hernández de Tejada, Pérez, \& Marco, 2019). Finally, although the MESTA framework has guided the objectives, hypotheses, and interpretation of the results of our study, we would like to point out that this is only a preliminary study of the model. To confirm the validity of the MESTA, more complex statistical analyses (e.g., structural equations) are needed in future research.

We are aware that we only propose a theoretical model in this paper, and so future research will have to test whether adding a Meaning Centered Therapy component to CBT for ED would improve the efficacy of CBT. Thus, future randomized controlled treatment studies are necessary to test whether this new theoretical model is adequate to improve these treatments for ED.

In conclusion, the results of this study suggest that meaning in life could be considered an important variable in the maintenance of ED psychopathology. The results of the present study, along with the previously discussed literature, suggest that the MESTA could be a new framework to improve the understanding of maintenance factors in people with ED with low meaning in life.

\section{References}

Allen, K. L., Byrne, S. M., Oddy, W. H., \& Crosby, R. D. (2013). DSM-IV-TR and DSM-5 eating disorders in adolescents: Prevalence, stability, and psychosocial correlates in a population-based sample of male and female adolescents. Journal of Abnormal Psychology, 122(3), 720-732. doi: 10.1037/a0034004

American Psychiatric Association. (2013). Diagnostic and statistical manual of mental disorders (5th ed.) (DSM-5). Arlington, VA: Autor.

Arcelus, J., Mitchell, A. J., Wales, J., \& Nielsen, S. (2011). Mortality rates in patients with anorexia nervosa and other eating disorders: A meta-analysis of 36 studies. Archives of General Psychiatry, 68(7), 724-731. doi: 10.1001/archgenpsychiatry.2011.74

Baron, R. M., \& Kenny, D. A. (1986). The moderator-mediator variable distinction in social psychological research: Conceptual, strategic and statistical considerations. Journal of Personality and Social Psychology, 51, 1173-1182.

Brassai, L., Piko, B. F., \& Steger, M. F. (2015). A reason to stay healthy: The role of meaning in life in relation to physical activity and healthy eating among adolescents. Journal of Health Psychology, 20(5), 473-482. doi: 10.1177/1359105315576604

Brechan, I., \& Kvalem, I. L. (2015). Relationship between body dissatisfaction and disordered eating: Mediating role of self-esteem and depression. Eating behaviors, 17, 49-58. doi: 10.1016/j.eatbeh.2014.12.008

Brockmeyer, T., Holtforth, M. G., Bents, H., Kämmerer, A., Herzog, W., \& Friederich, H. C. (2013). The thinner the better: Self esteem and low body weight in anorexia nervosa. Clinical Psychology \& Psychotherapy, 20(5), 394-400. doi: 10.1002/cpp.1771

Bulik, C. M., Berkman, N. D., Brownley, K. A., Sedway, J. A., \& Lohr, K. N. (2007). Anorexia nervosa treatment: A systematic review of randomized controlled trials. International Journal of Eating Disorders, 40(4), 310-320. 
Cash, T. F. (2000). MBSRQ Users' Manual (3a rev.). Norfolk, VA.: Old Dominion University.

Cash, T. F. (2011). Cognitive behavioral perspectives on body image. In T. F. Cash, \& L. Smolak (Eds.), Body image: A handbook of science, practice, and prevention (pp. 3947). New York, NY: Guilford.

Castro, J., Toro, J., Salamero, M., \& Guimerá, E. (1991). The Eating Attitudes Test: Validation of the Spanish version. Psychological Assessement, 7, 175-190.

Costanza, A., Prelati, M., \& Pompili, M. (2019). The meaning in life in suicidal patients: The presence and the search for constructs a systematic review. Medicina, 55, 1-18. doi: 10.3390/medicina55080465

Crow. S., Peterson, C., Swanson, S., Raymond, N., Specker, S., Eckert, E., \& Mitchell, J. (2009). Increased mortality in bulimia nervosa and other eating disorders. American Journal of Psychiatry, 166, 1342- 1346. doi: 10.1176/appi.ajp.2009.09020247

Crumbaugh, J. C., \& Maholick, L. T. (1969). Manual of instructions for the Purpose in Life Test. Saratoga, CA: Viktor Frankl Institute of Logotherapy.

Cruz-Sáez, S., Pascual, A., Wlodarczyk, A., \& Echeburúa, E. (2018). The effect of body dissatisfaction on disordered eating: The mediating role of self-esteem and negative affect in male and female adolescents. Journal of Health Psychology,25(8), 10981108. doi: / $10.1177 / 1359105317748734$

Fairburn, C. G. (2008). Cognitive behavior therapy and eating disorders. New York, NY: Guilford.

Fairburn, C. G., Cooper, Z., Doll, H. A., O'Connor, M. E., Bohn, K., Hawker, D., Wales, J. A., \& Palmer, R. L. (2009). Transdiagnostic cognitive-behavioural therapy for patients with eating disorders: A two-site trial with 60-week follow-up. American Journal of Psychiatry, 166, 311-319. doi: 10.1176/appi.ajp.2008.08040608

Fava, G. A. (2016). Well-being therapy: Current indications and emerging perspectives. Psychotherapy and Psychosomatics, 85, 136-145. doi: 101159/000444114

First, M. B., Gibbon, M., Spitzer, R. L., Williams, J. B. W., \& Benjamin, L. S. (1999). Entrevista clínica estructurada para los trastornos del eje II del DSM-IV [Structured Clinical Interview for DSM-IV Axis II Personality Disorders (SCID-II)]. Barcelona: Masson. (Orig. 1997).

First, M. B., Williams, J. B., Benjamin, L. S., \& Spitzer, R. L. (2015). User's guide for the SCID5-PD: Structured Clinical Interview for DSM-5 Personality Disorders. Washington, DC: American Psychiatric Association.

First, M. B., Williams, J. B. W., Karg, R. S., \& Spitzer, R. L. (2016). Structured Clinical Interview for DSM-5 Disorders - Clinician Version (SCID-5-CV). Washington, DC: American Psychiatric Association.

Fox, A. P., \& Leung, N. (2009). Existential well being in younger and older people with anorexia nervosa-A preliminary investigation. European Eating Disorders Review, 17(1), 24-30. doi: 10.1002/erv.895

Forrest, L. N., Jones, P. J., Ortiz, S. N., \& Smith, A. R. (2018). Core psychopathology in anorexia nervosa and bulimia nervosa: A network analysis. International Journal of Eating Disorders, 51(7), 668-679. doi: 10.1002/eat.22871

Frankl, V. E. (1959). Man's search for meaning: From death camp to existentialism (1 ${ }^{\mathrm{a}}$ ed.). New York, NY: Beacon.

Frankl, V. E. (2006). The unheard cry for meaning. Psychotherapy and humanism. Boston, MA: Beacon.

García Alandete, J., Gallego Hernández de Tejada, B., Pérez Rodríguez, S., \& Marco Salvador, J. H. (2019). Meaning in life among adolescents: Factorial invariance of the 
purpose in life test and buffering effect on the relationship between emotional dysregulation and hopelessness. Clinical Psychology \& Psychotherapy, 26(1), 24-34. doi: 10.1002/cpp.2327

García-Alandete, J., Rosa, E., \& Sellés, P. (2013). Estructura factorial y consistencia interna de una versión española del Purpose-in-Life Test [Factorial structure and internal consistency of a Spanish version of the Purpose-In-Life Test]. Universitas Psychologica, 12(2), 517-530. doi: 10.11144/218

Garner, D. M., \& Bemis, K. M. (1982). A cognitive-behavioral approach to anorexia nervosa. Cognitive Therapy and Research, 6(2), 123-150. doi: 10.1007/bf01183887

Garner, D.M., \& Garfinkel, P. E. (1979). The Eating Attitudes Test: An index of the symptoms of anorexia nervosa. Psychological Medicine 9, 273- 279. doi: $10.1017 / 50033291700030762$

Gillies, J., \& Niemeyer, R. A. (2006). Loss, grief, and the search for significance: Toward a model of meaning reconstruction in bereavement. Journal of Constructivist Psychology, 19, 31-65. doi: 10.1080/10720530500311182

Glaw, X., Kable, A., Hazelton, M., \& Inder, K. (2017). Meaning in life and meaning of life in mental health care: An integrative literature review. Issues in Mental Health Nursing, 38(3), 243-252. doi 10.1080/01612840.2016.1253804

Gongora, V. (2014). Satisfaction with life, well-being, and meaning in life as protective factors of eating disorder symptoms and body dissatisfaction in adolescents. Eating Disorders: The Journal of Treatment \& Prevention, 22, 435-449. doi: 10.1080/10640266.2014.931765

Gordon, C. S., Rodgers, R. F., Slater, A. E., Mclean, S. A., Jarman, H. K., \& Paxton, S. J. (2020). A cluster randomized controlled trial of the some social media literacy body image and wellbeing program for adolescent boys and girls: Study protocol. Body Image, 33, 27-37. doi: 10.1016/j.bodyim.2020.02.003

Grouden, M. E., \& Jose, P. E. (2014). How do sources of meaning in life vary according to demographic factors? New Zealand Journal of Psychology, 43(3), 29-38.

Gulliksen, K. S., Nordbø, R. H., Espeset, E. M., Skårderud, F., \& Holte, A. (2017). Four pathways to anorexia nervosa: Patients' perspective on the emergence of AN. Clinical psychology \& psychotherapy, 24(4), 846-858. https://doi.org/10.1002/cpp.2050

Hay, P. (2013). A systematic review of evidence for psychological treatments in eating disorders: 2005-2012. International Journal of Eating Disorders, 46(5), 462-469. doi: 10.1002/eat.22103

JASP Team. (2019). JASP (Version 0.11.1) [Computer software].

Lambert, N., Stillman, T., Baumeister, R., Fincham, F., Hicks, J., \& Graham, S. (2010). Family as a salient source of meaning in young adulthood. Journal of Positive Psychology, 5(5), 367-376. doi: 10.1080/17439760.2010.516616

Lorca, F., Pérez, S., Giner, F., \& Marco, J. H. (2019). What dimension of meaning in life is the stronger predictor of borderline personality disorder symptom? Journal of Constructivist Psychology. doi: 10.1080/10720537.2019.1697912

Macdonald, P., Hibbs, R., Corfield, F., \& Treasure, J. (2012). The use of motivational interviewing in eating disorders: A systematic review. Psychiatry Research, 200(1), 1 11. doi: 10.1016/j.psychres.2012.05.013

Maffei, C., Fossati, A., Agostoni, I., Barraco, A., Bagnato, M., Donati, D., Namia, C., Novella, L., \& Petrachi, M. (1997). Interrater reliability and internal consistency of the structured clinical interview for DSM-IV axis II personality disorders (SCID-II), version 2.0. Journal of Personality Disorders, 11(3), 279-284. doi: 10.1521/pedi.1997.11.3.279. 
Marco, J. H., Cañabate, M., Llorca, G., \& Pérez, S. (2020). Meaning in life moderates hopelessness, suicide ideation, and borderline psychopathology in participants with eating disorders: A longitudinal study. Clinical Psychology \& Psychotherapy. 27, 146158. doi: $10.1002 /$ cpp. 2414

Marco, J. H., Cañabate, M., Pérez, S., \& Llorca, G. (2017). Associations among meaning in life, body image, psychopathology, and suicide ideation in Spanish participants with eating disorders. Journal of Clinical Psychology, 73(12), 1768-1781. doi: 10.1002/jclp.22481

Marco, J. H., García-Alandete, J., Pérez, S., \& Botella, C. (2014). El sentido de la vida como variable mediadora entre la depresión y la desesperanza en pacientes con trastorno límite de la personalidad [The meaning in life as mediating variable between depression and hopelessness in patients with borderline personality disorder]. Behavioral Psychology/Psicología Conductual, 22(2), 291-303.

Martela, F., \& Steger, M. F. (2016). The three meanings of meaning in life: Distinguishing coherence, purpose, and significance. Journal of Positive Psychology, 11(5), 531-545. https://doi.org/10.1080/17439760.2015. 1137623

Martín, F. M., Cangas, A. J., Pozo, E. M., Martínez, M., \& López, M. (2008). Trastornos de la conducta alimentaria y personalidad: Un estudio comparativo. [Eating disorders and personality: A comparative study]. Behavioral Psychology/Psicología Conductual, 16(2), 187-203.

National Institute for Health and Care Excellence. (2017). Eating disorders: Recognition and treatment. NICE.

Neimeyer, R. A. (2000). Lessons of loss: A guide to coping. Clayton South: Centre for Grief Education.

Orbach, I., \& Mikulincer, M. (1998). The Body Investment Scale: Construction and validation of a body experience scale. Psychological Assessment, 10(4), 415-425. doi: 10.1037/1040-3590.10.4.415

Osório, F. L., Loureiro, S. R., Hallak, J. E. C., Machado-de-Sousa, J. P., Ushirohira, J. M., Baes, C. V., Apolinario, T.D, Donadon, M.F., Bolsoni, L.V., Guimaraes, T., Fracon, V.S., Casagrande, A.P., Aguiar-Pizeta, F., Mascarenhas-Souza, R., Faria-Sanches, R., dossantos, R., Martin-Santos, R., \& Crippa, J. A. S. (2019). Clinical utility and inter-rater and test-retest reliability of the Structured Clinical Interview for DSM-5 - Clinician Version (SCID-5-CV). Psychiatry and Clinical Neurosciencies, 73 (12), 754-760. https://doi.org/10.1111/pcn.12931

Park, C. L. (2010). Making sense of the meaning literature: An integrative review of meaning making and its effects on adjustment to stressful life events. Psychological Bulletin, 136(2), 257-301. doi: https://doi.org/10.1037/a0018301

Perpiñá, C., \& Borra, C. (2010). Estima corporal y burlas en mujeres con atracones: Desarrollo de una imagen corporal negativa [Body-esteem and teasing in female binge-eaters: Developing a negative body image]. Behavioral Psychology/Psicología Conductual, 18(1), 91-104.

Pike, K. M., \& Olmsted, M. P. (2016). Cognitive behavioral therapy for severe and enduring anorexia nervosa. In S. Touyz, D. Le Grange, H. Lacey, \& P. Hay (Eds.), Managing severe and enduring anorexia nervosa: A clinician's guide (pp.128-145). Oxford: Routledge.

Robinson, P. H., Kukucska, R., Guidetti, G., \& Leavey, G. (2015). Severe and enduring anorexia nervosa (SEED AN): A qualitative study of patients with 20+ years of anorexia nervosa. European Eating Disorders Review, 23(4), 318-326. doi: 10.1002/erv.2367 
Roncero, M., Perpiña, C., Marco, J. H., \& Sanchez-Reales, S. (2015). Confirmatory factor analysis and psychometric properties of the Spanish version of the Multidimensional Body-Self Relations Questionnaire-Appearance Scales. Body Image, 14, 47-53. doi: 10.1016/j.bodyim.2015.03.005

Rosewall, J. K., Gleaves, D. H., \& Latner, J. D. (2020). Moderators of the relationship between body dissatisfaction and eating pathology in preadolescent girls. The Journal of Early Adolescence, 40(3), 328-353. doi: 10.1177/0272431619837385

Schulenberg, S. E., Strack, K. M., \& Buchanan, E. M. (2011). The Meaning in Life Questionnaire: Psychometric properties with individuals with serious mental illness in an inpatient setting. Journal of Clinical Psychology, 67(12), 1210-1219. doi: 10.1002/jclp.20841

Scott, T. M., \& Snyder, C. R. (2005). Getting unstuck: The roles of hope, finding meaning, and rumination in the adjustment to bereavement among college students. Death Studies, 29 (5) 435-458. doi: 10.1080/07481180590932544

Serpell, L., Treasure, J., Teasdale, J., \& Sullivan, V. (1999). Anorexia nervosa: Friend or foe? International Journal of Eating Disorders, 25(2), 177-186. doi: 10.1002/(SICI)1098108X(199903)25:2<177::AID-EAT7>3.0.CO;2-D

Smink, F. R., van Hoeken, D., \& Hoek, H. W. (2013). Epidemiology, course, and outcome of eating disorders. Current Opinion in Psychiatry, 26(6), 543-548. doi: 10.1097/YCO.0b013e328365a24f

Steger, M. F., Oishi, S., \& Kashdan, T. B. (2009). Meaning in life across the life span: Levels and correlates of meaning in life from emerging adulthood to older adulthood. The Journal of Positive Psychology, 4(1), 43-52. doi: 10.1080/17439760802303127

Stein, K. F., \& Corte, C. (2007). Identity impairment and the eating disorders: Content and organization of the self-concept in women with anorexia nervosa and bulimia nervosa. European Eating Disorders Review, 15, 58-69. doi: 10.1002/erv.726.

Steinhausen, H. (2002). The outcome of anorexia nervosa in the 20th century. American Journal of Psychiatry 159, 1284-1293.doi: 10.1176/appi.ajp.159.8.1284

Stice, E. (2016). Interactive and mediational etiologic models of eating disorder onset: Evidence from prospective studies. Annual Review of Clinical Psychology, 12(1), 359381. doi: 10.1146/annurev-clinpsy-021815-093317

Stice, C.N. Marti, \& S. Durant (2011) Risk factors for onset of eating disorders: Evidence of multiple risk pathways from an 8-year prospective study. Behaviour Research and Therapy, 49, 622-627. doi: 10.1016/j.brat.2011.06.009

Stice, E., South, K., \& Shaw, H. (2012). Future directions in etiologic, prevention, and treatment research for eating disorders. Journal of Clinical Child \& Adolescent Psychology, 41, 845-855. doi: 10.1080/15374416.2012.728156

Striegel-Moore, R. H., \& Bulik, C. M. (2007). Risk factors for eating disorders. American psychologist, 62(3), 181-198.

Tomba, E, Tecuta, L., Schumann, R., \& Ballardini, D. (2017). Does psychological well-being change following treatment? An exploratory study on outpatients with eating disorders. Comprehensive Psychiatry, 74, 61-69. doi 10.1016/j.comppsych.2017. 01.001

Touyz, S., \& Hay, P. (2015). Severe and enduring anorexia nervosa (SE-AN): In search of a new paradigm. Journal of Eating Disorders, 3(26). https://doi.org/10.1186/s40337015-0065-z 
Vitousek, K. B., \& Ewald, L. S. (1993). Self-representation in eating disorders: A cognitive perspective. In Z. V. Segal y S. J. Blatt (Eds.), The self in emotional distress: Cognitive and psychodynamic perspectives. (pp. 221-266). New York, NY: Guilford.

Volkert, J., Schulz, H., Brütt, A. L., \& Andreas, S. (2014). Meaning in life: Relationship to clinical diagnosis and psychotherapy outcome. Journal of Clinical Psychology, 70(6), 528-535. doi: 10.1002/jclp.22053

Wong, P. T. P. (1998). Implicit theories of meaningful life and the development of the Personal Meaning Profile (PMP). In P. T. P. Wong, \&. Fry (Eds.), The human quest for meaning: A handbook of psychological research and clinical applications (pp. 111140). Mahwah, NJ: Erlbaum.

Received: April 26, 2020

Accepted: August 28, 2020 


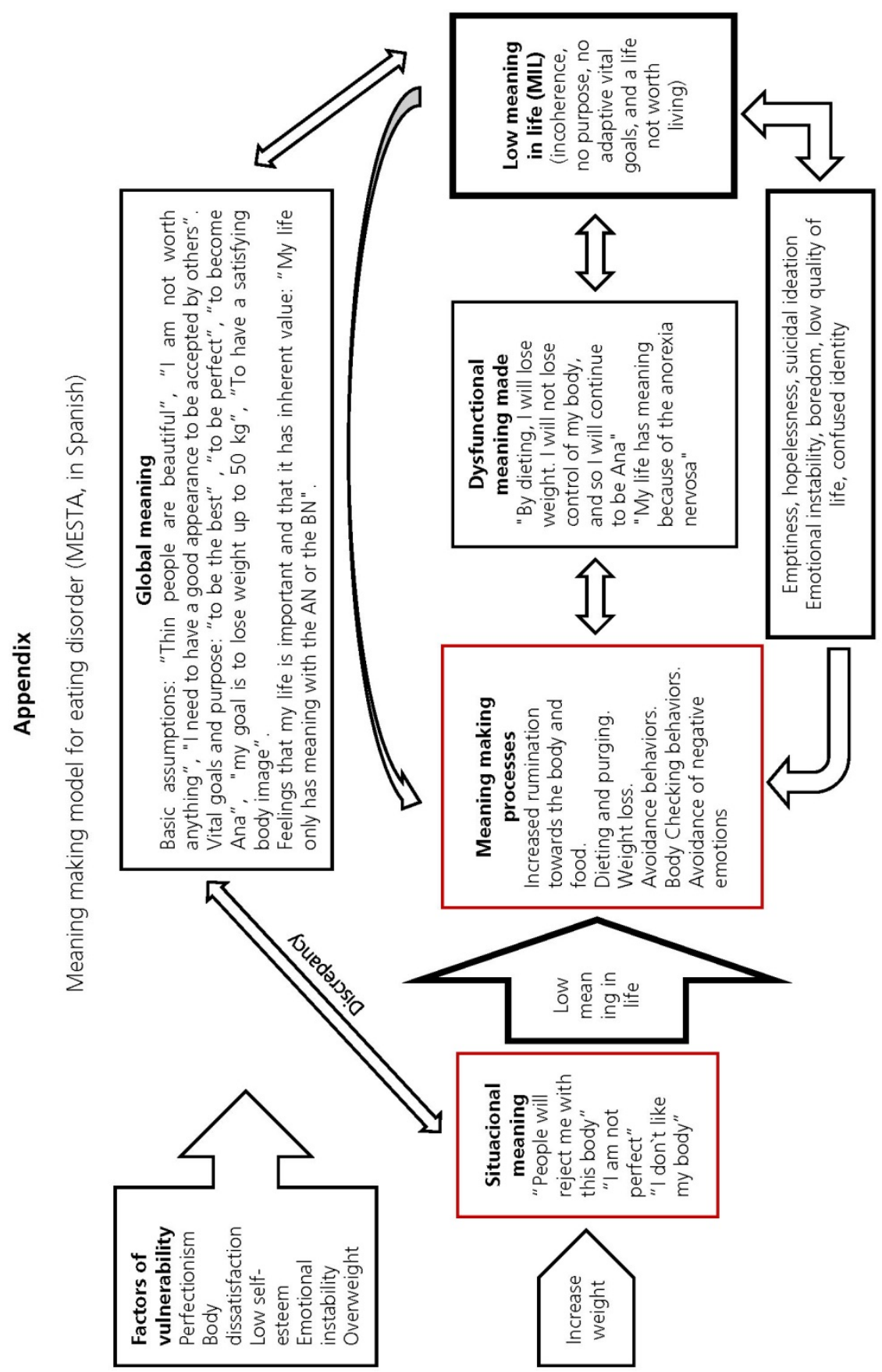


